\title{
THE CREATION AND EARLY HISTORY OF THE BERKELEY STATISTICS DEPARTMENT
}

\author{
E. L. LEHMANN \\ Educational Testing Service and University of California, Berkeley
}

\begin{abstract}
This paper sketches the development of the Berkeley statistics group from Neyman's appointment as Professor of Mathematics in 1938 to its status as an independent Department of Statistics in 1955. It ends with a brief description of Neyman's resignation as chair of the Department in 1956 and its transition to a new era under the chairmanship of David Blackwell.
\end{abstract}

1. The Beginning. In her Neyman biography, ${ }^{1}$ Constance Reid describes how in 1934 the University of California brought Griffith Evans ${ }^{2}$ to Berkeley to revitalize its Mathematics Department. She mentions Evans' early interest in statistics, and tells of his search for a suitable statistician, which ended with his offering a position to Jerzy Neyman. ${ }^{3}$ Evans took some risk with this offer since he had never met Neyman. But I believe Neyman fulfilled his expectations as a serious and original scientist, interested in both the mathematical theory of statistics, and the broad spectrum of its applications. He also turned out to be an ambitious and dynamic administrator, sometimes perhaps more so than Evans had bargained for.

On Neyman's part, the risk was of course also very great. He had never been to California and knew little about its University except the - to him very attractive - fact that it had as yet no statistics program. However, he quickly came to like both Berkeley and the University, and he does not seem to have had any later regrets.

Neyman arrived in the summer of 1938 to take up a position as Professor of Mathematics, with the specific responsibility of developing a statistics program and of assisting Berkeley faculty members with the statistical problems they might encounter in their work.

Over the next three years, he set up a skeleton teaching program and acquired a few graduate students who, as Teaching Assistants, helped with the laboratories attached to the courses. He also engaged in a steadily increasing amount of consulting work with various faculty colleagues, which he enjoyed and which was much appreciated. For the Assistants, his secretary, 
and the calculators that were needed for teaching and research, he was provided with a number of rooms. He dubbed his organization the Statistical Laboratory ("The Lab") and soon obtained official status for it, with himself as Director.

Further progress was halted with the coming of World War II during which all his energy was absorbed by war work. As a result, when the war ended in 1945, the statistical faculty still consisted of just one person: Neyman as Professor of Mathematics and Director of the Statistical Laboratory. Ten years later it had grown to ten tenured or tenure track faculty members who formed a separate Department of Statistics, independent of the Mathematics Department. How was it possible in so short a time to achieve such a spectacular development?

2. A Period of Growth. Building a substantial program required attention to many different aspects: Faculty, students, support staff, equipment, space, and-very importantly-the reputation of the group both within and outside the University. Each of these presented its own problem.

(i) Faculty. One question Neyman had to face if he wanted to assemble a teaching staff, was from where to recruit his faculty. A natural pool-his own students who were trained in his still quite novel approach to statisticswas problematical because the University strongly discouraged departments from hiring their own Ph.D.students. Neyman overcame this difficulty by persuading the administration that this was the principal source available to him since few other universities were turning out students he considered satisfactory.

As a result, during the next several year he appointed to the faculty, as they completed their degrees: Lehmann (1946), Barankin (1947), who was enrolled in the statistics program but wrote his thesis in algebra, Fix and Scott (1950), Hodges (1951), and Le Cam (1952). In addition, he made some superb appointments from the outside: Stein (1947) who came with a fresh degree from Columbia and was familiar with Wald's ideas, Loève (1948) to develop the probability program, Scheffé (1953), and Blackwell (1955).

A faculty, half of which has been trained by its senior member, presents two dangers: That of inbreeding, which may result in a certain narrowness, and-in the other direction-difficulties as former students become independent colleagues. Although in this case the first of these dangers was somewhat mitigated by the very strong outside appointments, a certain narrowness did result. There was a lack of attention to any Fisherian or Bayesian aspects, and in general the program reflected the Neyman-Pearson-Wald point of view so strongly that Lindley (1990), in his Wald lectures, referred to this approach simply as "Berkeley". This weakness was at the same time 
a source of strength. It resulted in a congenial group which shared a basic point of view and which engaged in much collaborative work. ${ }^{4}$ As we shall see later, the second difficulty mentioned above, eventually also caused some problems.

(ii) Students and Courses. The expansion of the teaching staff made possible a corresponding broadening of the offerings of both theoretical and applied courses. The resulting increase in enrollments, in turn, justified further faculty appointments. Although the statistics group never obtained a monopoly in the teaching of statistics, Neyman cooperated closely with the applied departments that sent him students, and gradually persuaded other departments to relinquish their lower division courses so that, eventually, nearly all lower division teaching of statistics, involving several thousand students, was done by the members of the Statistical Laboratory.

(iii) The Symposia. As the war ended in 1945, Neyman was elated at the prospect of returning to free scientific research. To celebrate the occasion, he proposed a meeting "to mark the end of the war and to stimulate the return to theoretical research". He issued invitations to statisticians all over the country, and the result was the Berkeley Symposium on Mathematical Statistics and Probability, August 13-18, 1945. The majority of the speakers came from the various campuses of the University of California, but the participants also included such luminaries as Doob, Feller, Hotelling,Hsu, Pólya, and Wolfowitz. The papers were published in a Proceedings Volume which ran to 501 pages.

Not only Neyman, but also Evans and the university administration considered the symposium a great success and agreed to his request for financial support for a second symposium to be held in 1950. This second meeting had an even broader cast, including some speakers from abroad, among them Cramér, De Finetti, Dvoretzky, Erdös, Fortet and Paul Lévy. The table of contents of the Proceedings volume, reflecting Neyman's wide interests, was divided by subject matter: Mathematical statistics, probability, astronomy, biometry, econometrics, physics, traffic engineering, and wave analysis. At the conclusion of the Preface Neyman looked "forward to a third symposium within a few years."

Thus started a tradition of symposia, which were held every five years (until 1970). They became the principal international statistical meetings during this period, and were an important factor in establishing an international reputation for Berkeley as an important statistical center.

These various aspects of the program were driven by Neyman's energy and involved an unending flurry of activities on his part. Providing his staff with space (as the group grew we were constantly on the move), equipment, summer support, promotions; dealing with a stream of consulting 
problems; organizing not only the symposia and the publication of their proceedings, but also developing a serial publication (The University of California Publications in Statistics); arranging summer sessions with distinguished visitors-one gets dizzy just enumerating them and wonders at the prodigious amount of energy Neyman was able to muster. But this effort achieved its end; the group grew steadily, and Berkeley acquired an international reputation as a first-rate center of mathematical statistics.

Yet, even Neyman's energy and talent could not have generated this sustained development without the support of an outside factor: the growing importance of the field of statistics itself. Statistics had proved its usefulness during the war and now was expanding in ever widening circles in universities, industry and government. The nature of the subject was changing from a primarily descriptive to an inferential mode in which the new approaches developed by Fisher, Neyman and Pearson played a central role. Correspondingly, there was increased demand for statistical services (both teaching and consulting) throughout the University, which greatly strengthened Neyman's hand in his negotiations with the administration.

3. From Lab to Department. In the efforts on behalf of his laboratory, Neyman usually had the support of Evans, but on one issue they strongly disagreed, and the resulting conflict was a cause on continuing tension. From the start, Neyman had envisioned a Department of Statistics which would be independent of the Mathematics Department. In contrast, Evans was trying to create a broad-based Mathematics Department that would contain all the mathematical sciences: Not only pure and applied mathematics, but also areas such as statistics, logic and actuarial and computer science.

One reason for Neyman's drive for independence was undoubtedly his strong personal desire for freedom from outside controls. He liked to be the master of his fate. For publishing his papers, in order to avoid the interference of editors who might not approve of his ideas or his style, he instituted a series that would be under his control. Similarly, he did not want to have to clear his appointments or his budget with a chairman who might have different views.

There was, however, a second more objective reason. Although Neyman had played a central role in the mathematifization of statistics, he felt that statistical theory - unlike mathematics-needed to be motivated by its importance and usefulness for applications, and that this applied orientation led to attitudes and value judgments different from those held by mathematicians. He thus considered statistics to be a distinct subject, and believed that it could develop more naturally in a separate department. In addition, the departmental status would provide the emerging subject with greater visibil- 
ity and recognition. This conclusion came to be shared by other statisticians and eventually led to the establishment of separate departments of statistics in most American universities.

Convinced of the righteousness and importance of his cause, Neyman pressed relentlessly for greater independence for the Lab. Occasional disagreements with Evans about specific issues, offers from other universities, all were used to obtain, step by step, official recognition of the Lab, a separate budget, greater authority in hiring, etc. until in the end, the connection with the mathematics department became little more than a formality.

Under these circumstances, when Evans retired from the chairmanship in 1949, his successor (Charles Morrey) no longer opposed the separation of the two groups, and recommended the formation of a separate department of statistics. But in Berkeley the administrative wheels grind slowly, and it took another five years until, in 1954, the Berkeley Chancellor (Clark Kerr) and the President of the university (Gordon Sproul), and finally in 1955 the Board of Regents, approved the new arrangement.

4. Two Crises. The steady progress from the appointment of Neyman in 1938 as Professor of Mathematics to the establishment of a separate department, the faculty of which would eventually attain a size of over 20, was interrupted by two crises, each of which had the potential to destroy much of what had been achieved by then.

The University of California is governed by an independent Board of Regents. However, it depends on funds appropriated by the state government in Sacramento, and in addition, most of the regents are appointed by the Governor. In politically turbulent times, Sacramento, therefore, can make its influence felt. Such an occasion arose during the MacCarthy period. In order to preempt legislation proposed by the State Unamerican Activities Committee, which would have deprived the university of some of its authority, in 1950 the Regents voted to require from university faculty and staff, an anticommunist oath. Many faculty members considered such a special oath offensive and demeaning, and a number (in the end about 30 ) refused to comply. After an extended, bitter struggle, the regents voted to dismiss the non-signers. ${ }^{5}$ Most members of the statistics group (including Neyman) signed with distaste. However, Charles Stein decided instead to leave the university. (After some years in Chicago, he returned to California, but to Stanford rather than Berkeley.)

The conflict deeply split the faculty of the university and poisoned the atmosphere. To escape the turmoil, Hodges and Lehmann took extended leaves. Several members of the group received attractive offers from other universities; Scheffé whom Neyman tried to bring to Berkeley, refused his 
offer. The outlook was bleak and Neyman so pessimistic that he tried (unsuccessfully) to move the whole group to another university.

By mid-1951, the Legislature had removed the motive for the University oath by requiring an anticommunist oath of all state employees. In addition, changes had occurred on the Board of Regents, and the Board rescinded the special oath. With the exception of Stein, no member of the group had left, and Scheffé accepted a renewed offer. The cohesiveness and loyalty that Neyman had built, together with the attractiveness of Berkeley, had been strong enough for the Lab to survive.

The second crisis occurred during the year following the creation of the department when Neyman, completely unexpectedly, announced his resignation as chair of the new department. Chancellor Kerr persuaded him to withdraw his resignation, but a few months later he renewed it and this time remained firm. It must have been a difficult decision for him, and his reasons undoubtedly were complex, but two stand out.

One motive was a wish to return to the kind of work he had enjoyed so much as a younger man. The twenty-year period since then had been devoted to the building of the Berkeley statistics group and had left little time and energy for his research. He was now 61 , and if he still wanted to do some major research, this was the time to do it.

A second reason for relinquishing the responsibility for the department was a gradual change that had developed in his relations with the group. His former students had grown up, had acquired new responsibilities and their own views on issues, which did not always agree with his. He was still the "grand old man", but conflicts and tensions had arisen which Neyman found bothersome. Under these circumstances he preferred to keep as his domain, the laboratory, separated from the department, and completely under his control, and to leave the running of the department to his younger colleagues.

Complete separation of the two operations was, of course, not possible. Neyman's laboratory was in charge of all grants, with a research budget that was about equal in size to the budget of the department. Research and teaching assistants came from a common pool, and there were many other points of contact and possible conflict. With authority thus divided, it was essential that the new chair get along well with both Neyman and the rest of the group. The obvious person for the position was David Blackwell who had spent 1954/55 in Berkeley as a visitor, and had joined the permanent faculty the following year. ${ }^{6}$ Blackwell was respected and liked by everyone. He had a good way of dealing with little difficulties by not taking them too seriously. Perhaps it was also an advantage that as a relative newcomer, he had not been involved in earlier disagreements. In any case, it turned out to be a great choice. Blackwell managed the transition in a smooth 
and gracious way, and steered the statistics department onto its new course without a serious break of continuity, thus confounding the predictions of many professional colleagues who expected the department to disintegrate after Neyman's resignation.

David has now been an admired and respected colleague for over forty years, and it is a great pleasure to dedicate to him these memories of earlier times in friendship and with affection.

${ }^{1}$ Constance Reid's indispensable book, Neyman-from life, tells the story of Neyman's life and of the department he created. I have repeatedly drawn on her account to check, bolster, and sometimes correct my own memories.

${ }^{2}$ Griffith Conrad Evans (1887-1973) was one of the most distinguished mathematicians of his generation. (Among other honors he was Colloquium Lecturer of the American Mathematical Society (1916), was elected to the National Academy of Sciences (1933), and served as President of the American Mathematical Society (1938-1940).) He came to the University of California, Berkeley in 1934 to chair its mathematics department, which at the time was in the doldrums. During the 15 years of his chairmanship, he developed the department into a first-rate institution. Evans retired in 1955 and when later the university decided on a new building to house the mathematics and statistics departments, it was named Evans Hall.

For a more detailed account of Evan's life and accomplishments, see Rider (1990). Some of my own memories of Evans can be found in Lehmann (1993).

${ }^{3}$ For more details on Neyman's life, see Reid (1982) and Lehmann (1990).

${ }^{4}$ At one time or another, there were joint papers by Blackwell and Hodges; Fix and Hodges; Fix, Hodges, and Lehmann; Hodges and Le Cam, and Lehmann and Stein. In addition, there were long collaborations by Neymann and Scott and by Hodges and Lehmann.

${ }^{5}$ Eventually the State Supreme Court ruled against the Regents. A detailed account of the very complicated history of this struggle, is provided by Gardner (1967).

${ }^{6}$ Neyman had in fact tried to bring Blackwell to Berkeley once before. In 1942 he was looking for a young faculty member and Doob had recommended Blackwell as an outstanding student. Neyman had obtained the agreement of Evans who, however, shortly thereafter told Neyman that Blackwell's race would cause difficulties in the department. His own wife, a southerner, had said that she would not feel able to invite Blackwell to her house. Neyman, not wanting to cause dissension in the department that had been so hospitable to him, and administratively dependent on Evans, backed down. I am happy to be able to add that David recently told me that later, after he joined the statistics department, Mr. and Mrs. Evans did invite him and his wife Ann to their house and that it was a very pleasant evening.

\section{REFERENCES}

Gardner, D. (1967). The California Oath Controversy. University of California Press, Berkeley, CA.

Lehmann, E. L. (1990). Jerzy Neyman, 1894-1981. Dictionary of Scientific Biography, 18 669-674. 
Lehmann, E. L. (1993). Mentors and early collaboration. Statistical Science 8 331-341.

Lindley, D. V. (1990). The 1988 Wald Memorial Lectures: The present position in Bayesian statistics. Statistical Science 5 44-65.

REID, C.(1982). Neyman-from Life. Springer, New York.

Rider, R. E. (1990). Griffith Conrad Evans, 1887-1973. Dictionary of Scientific Biography, 17 270-272.

\author{
E. L. LeHMANN \\ Department of Statistics \\ UNIVERSITY OF CALIFORNIA \\ BERKELEY, CA 94702
}

